\title{
HUBUNGAN RELIGIUSITAS DAN KEWIRAUSAHAAN : SEBUAH KAJIAN EMPIRIS DALAM PERSPEKTIF ISLAM
}

\author{
Fauzan \\ Email : gus_zain2001@yahoo.com
}

\begin{abstract}
Abstrak : Agama dan pembangunan ekonomi merupakan hal yang tidak bisa dipisahkan. Beberapa penelitian menyatakan bahwa agama memiliki dampak pada pembangunan ekonomi. Namun, sedikit penelitian yang mengkaji tentang bagaimana agama memberikan dampak pada keputusan individu. Karya ini mengkaji hubungan agama dan kewirausahaan. Berdasarkan kajian teoritis pada penelitian-penelitian sebelumnya, karya ini menemukan bahwa agama memiliki hubungan terhadap keputusan kewirausahaan. Secara khusus, agama Islam sangat kondusif untuk memerintahkan umatnya untuk berwirausaha. Dengan demikian, bukti-bukti empiris menunjukkan bahwa agama mempengaruhi perilaku ekonomi, dan memiliki hubungan dengan perilaku berwirausaha.
\end{abstract}

Kata kunci : Religiusitas, Kewirausahaan, Islam

\section{PENDAHULUAN}

Kewirausahaan di Negara berkembang merupakan tiang penyangga dunia usaha dan industri. Kewirausahaan adalah kemampuan dan kemauan seorang untuk berisiko dengan menginvestasikan dan mempertaruhkan waktu, uang dan usaha untuk memulai suatu usaha dan menjadikannya berhasil. Seorang entrepreneur menjalankan bisnis sebagai kepuasan (self actualitation) dan mencari keuntungan (profit oriented).

Kewirausahaan adalah konsep yang sangat kompleks, dan dapat dijelaskan dengan berbagai perspektif yang berbeda. Para penulis dalam memahami kewirausahaan menggunakan berbagai perspektif diantaranya, kewirausahaan dilihat berdasarkan sikap kewirausahaan (Fitzsimmons \& Douglas, 2005; Robinson, Stimpson, Huefner, \& Hunt, 1991; Shariff \& Saud, 2009), proses (Lumpkin \& Dess, 1996; Stevenson \& Jarillo, 1990) dan perilaku (Covin \& Slevin, 1991; Zahra, 1993). Berbagai perspektif ini telah diterima secara luas dan telah digunakan untuk kepentingan yang berhubungan dengan pencapaian kinerja perusahaan. Dalam perspektif sikap kewirausahaan, seperti yang dijelaskan oleh Robinson, et al. (1991), adalah kemampuan kewirausahaan dalam menciptakan posisi persaingan dan menempatkan perusahaan dalam pasar atau industri di mana mereka menjalankan kegiatan bisnis.

Fauzan, adalah Dosen Prodi Akuntansi Universitas Kanjuruhan Malang 
Kewirausahaan yang didasarkan pada proses mencerminkan upaya dari individu untuk mengidentifikasi sejumlah peluang yang ada di pasar dan menjelaskan sumber daya yang dibutuhkan untuk mengeksploitasi sumber daya (Hill \& Wright, 2000). Dengan demikian, perspektif ini melalui tiga tahap utama dalam proses kewirausahaan, yaitu: persepsi dan komitmen untuk mencari peluang, mengejar peluang, dan komitmen. Beberapa peneliti juga menjelaskan bahwa perspektif ini ditandai oleh input dan output (Morris, Lewis, \& Sexton, 1994). Input digambarkan dengan kemampuan kewirausahaan untuk menangkap peluang dari lingkungan yang dihadapi organisasi dan individu, konteks, pelaksanaan konsep bisnis serta penggunaan beberapa sumber daya keuangan dan non keuangan. Sementara output yang berkaitan dengan proses pembuatan produk-produk baru dan jasa, pencapaian laba pertumbuhan aset, serta kegagalan.

Kewirausahaan yang didasarkan pada perilaku adalah, kewirausahaan yang ditunjukkan oleh kemampuan kewirausahaan untuk mendeteksi peluang dan kemampuan untuk memotivasi dalam mencapai peluang (Botsaris \& Vamvaka, 2012; Duygulu \& Kurgun, 2009). Selain itu, kewirausahaan yang didasarkan pada perilaku akan mendorong seseorang untuk menunjukkan, mengevaluasi dan memanfaatkan kesempatan (Shane \& Venkataraman, 2000).

Agama dan aktivitas usaha memiliki hubungan yang komplek dan saling tergantung ( Carswell \& Rolland, 2007). Penelitian-penelitian terkini mengenai hubungan agama dan kewirausahaan menunjukkan bahwa agama mempengaruhi aktivitas kewirausahaan ( Galbraith \& Galbraith, 2007; Noble, Galbraith, Singh, \& Stiles, 2007; Valliere, 2008; Arief, 2013; Audretsch, Boente, \& Tamvada, 2007; Baharun \& Kamarudin, 2001; Balog, Baker, \& Walker, 2014; Dana, 2010). Mempengaruhi keputusan untuk menjadi pengusaha, manajemen perusahaan, dan jaringan antar pengusaha.

Pada saat ini fenomena kewirausahaan tidak hanya dijelaskan melalui pendekatan psikologi dan sosial yang menekankan pada inovasi, penciptaan bisnis baru, pengembangan bisnis, dan sifat kewirausahaan. Tapi penelitian-penelitian yang dilakukan sudah mengarahkan pada perspektif bahwa pengembangan kewirausahaan dapat diarahkan pada pendekatan agama ( Antoncic \& Hisrich, 2003; Halis, Ozsabuncuoglu, \& Ozsagir, 2007; Shane \& Venkataraman, 2000). Religiusitas telah menjadi isu penting dalam studi kewirausahaan dan manajemen (Zulkifli \& Rosli, 2013). Pendapat yang lain mengatakan bahwa keberhasilan kewirausahaan dalam meningkatkan kinerja sangat dipengaruhi oleh tingkat religiusitas wirausaha, dan religiusitas akan memiliki dampak pada sikap dan perilaku perbedaan dari wirausaha ( Carswell \& Rolland, 2007). Selain itu, religiusitas sebagai input dari budaya akan berperan dalam pengembangan kewirausahaan (Morrison, 2000).

Berdasarkan penjelasan di atas, kami berpendapat bahwa seseorang dengan tingkat religiusitas yang baik akan selalu berusaha untuk menjalankan kegiatan bisnis dengan lebih menekankan pada etika, moralitas, dan lebih peduli tentang lingkungan. Dengan demikian, ketika bisnis yang dijalankan berdasarkan religiusitas, kinerja yang unggul akan mudah dicapai (Iannaccone, 1998; Naughton \& Cornwall, 2009). 
Fauzan, Peranan UKM Menjalin Kemitraan 149

\section{TINJAUAN PUSTAKA}

\section{Religiusitas}

Religiusitas akan memberikan dampak pada perilaku individu. Sebagai contoh, beberapa orang mungkin akan menggunakan pendekatan manajerial dalam melaksanakan kegiatan usaha, sementara yang lain akan menggunakan pendekatan keyakinan (Audretsch et al., 2007). Untuk masyarakat Muslim, perilaku kewirausahaanya selalu didasarkan pada Al Qur'an dan Hadis. Oleh karena itu, Islam memberikan cara yang berbeda untuk mendapatkan keuntungan dan melayani Tuhan. Sudut pandang yang mungkin berbeda dengan tingkat perbedaan religiusitas akan mempengaruhi cara seseorang menafsirkan kehidupan, dalam mengambil keputusan yang ada serta lebih sensitif terhadap kondisi lingkungan yang ada di sekitarnya (Dilmaghani, 2011). Sejauh mana agama mempengaruhi keyakinan seseorang dan perilaku tergantung pada tingkat religiusitas individu dan pentingnya agama dalam kehidupan (Sood \& Nasu, 1995).

Agama didefinisikan sebagai tingkat moralitas dan cara pandang seseorang dalam memaknai kehidupan (Emami \& Nazari, 2012). Secara eksplisit, agama berkaitan dengan tingkat kepercayaan dan nilai-nilai yang dimiliki oleh seseorang dan sejauh mana mereka dapat menerapkan nilai-nilai dan keyakinan tersebut dalam kehidupannya (Worthington, Everett L. et al., 2003). Agama dapat diukur dari dua hal, yaitu menggunakan kognitif, dimiliki oleh seseorang dan perilaku yang akan ditunjukkan. Dalam konteks kegiatan usaha, agama akan menentukan konsistensi dari perilaku yang ditunjukkan oleh orang yang menjalankan bisnis, seperti praktek bisnis yang memberikan prioritas kepada etika, kejujuran dan terpercaya (Muhamad \& Mizerski, 2010).

Religiusitas didefinisikan sebagai tingkat keyakinan yang spesifik dalam nilai-nilai agama dan cita-cita yang diselenggarakan dan dipraktekkan oleh seorang individu. Religiusitas juga digambarkan sebagai kepercayaan kepada Tuhan (iman) yang disertai dengan komitmen untuk mengikuti prinsip-prinsip yang diyakini akan ditetapkan oleh Allah (McDaniel \& Burnett, 1990). Konsep religiusitas dapat dilihat dari dua komponen, yaitu afiliasi keagamaan dan agamanya. Afiliasi keagamaan adalah sekelompok individu yang memiliki tujuan yang sama dengan religiusitas untuk memperkuat statusnya (Worthington, Everett L. et al., 2003).

Beberapa peneliti menduga bahwa afiliasi keagamaan berhubungan dengan sistem kognitif yang dimiliki oleh individu, yang digambarkan sebagai seperangkat keyakinan, nilai-nilai, harapan, dan perilaku yang akan didistribusikan kepada semua anggota dalam kelompok. Sistem kognitif juga berhubungan dengan Spiritualisme yang menunjukkan tingkat individu dalam mempertahankan keyakinannya dalam pentingnya agama, kepercayaan Allah dan pentingnya nilainilai kepercayaan (Muhamad \& Mizerski, 2010). Implikasinya, ketika individu mampu mengubah sistem kognitif yang dimiliki kepada semua anggota Group, maka mungkin akan ada perubahan dari perilaku

\section{Religiosity dan Kewirausahaan}

Religiusitas mungkin mempengaruhi pilihan individu dalam melaksanakan aktivitas kewirausahaan (Audretsch et al., 2007). Selain itu, religiusitas akan 
bermanfaat untuk wirausaha dalam menghadapi perubahan lingkungan (Patel, 2003), sehingga akan mampu bertahan dalam lingkungan bisnis (Naugton). Secara empiris, beberapa peneliti menyatakan bahwa religiusitas akan memberikan dampak pada pencapaian kinerja yang unggul (Kohl, 1984) dan keberhasilan kewirausahaan (Makhbul \& Hasun, 2011; Shariff \& Saud, 2009). Selanjutnya menjelaskan bahwa faktor-faktor yang mendorong keberhasilan kewirausahaan dalam menjalankan kegiatan bisnis melalui religiusitas dengan kemampuan mereka untuk membuat keputusan mereka sendiri dan mereka kemampuan untuk mengendalikan organisasi memberikan kontribusi bagi keberhasilan mereka.

Dari perspektif manajemen, kewirausahaan ditandai sebagai individu yang memiliki kemampuan untuk menunjukkan perilaku yang inovatif, kemampuan untuk menciptakan bisnis baru ( Antoncic \& Hisrich, 2003). Seorang pengusaha harus memiliki kemampuan untuk mengatur, mengelola dan mengambil risiko. Sejalan dengan pendapat ini, beberapa peneliti diasumsikan bahwa kewirausahaan dapat diartikan sebagai karakter dari individu dalam menghadapi tantangan lingkungan yang tidak pasti melalui perkembangan inovatif perilaku (Covin \& Slevin, 1991).

Dari uraian diatas, kami menyimpulkan bahwa definisi kewirausahaan sangat normatif. Ketika sebuah bisnis beroperasi, kemudian beberapa bentuk perilaku tersebut diperlukan dalam mencapai kesuksesan bisnis. Dengan kata lain, kondisi ini tidak terjadi hanya di bidang kewirausahaan, yang dalam arti sempit banyak terkait dengan usaha kecil, tetapi mereka juga melakukan aktivitas untuk perusahaan berskala besar. Oleh karena itu, kewirausahaan dapat digambarkan sebagai individu yang memiliki nilai-nilai yang unik, sikap, keyakinan, dan kebutuhan, yang akan mendorong mereka untuk menjadi wirausaha sehingga akan membedakan dirinya dengan orang-orang yang bukan wirausaha (Kohl, 1984).

Beberapa penelitian empiris menunjukkan bahwa ada hubungan yang kuat antara religiusitas dan perilaku kewirausahaan ( Carswell \& Rolland, 2007; Audretsch et al., 2007; Dodd \& Gotsis, 2007; Dodd \& Seaman, 1998). Secara umum, religiusitas digambarkan sebagai seperangkat nilai-nilai, kepercayaan, norma, etika, dan perilaku yang harus dimiliki oleh seseorang dalam melaksanakan kegiatan usahanya. Beberapa studi ini memperkuat argumen bahwa nilai, kepercayaan dan norma-norma akan memiliki dampak pada orientasi kewirausahaan (Adamu, Kedah, \& Osman-gani, 2011; Bergman \& Brodd, 2014; Busenitz, Gómez, \& Spencer, 2000). Dengan demikian, analisis perilaku kewirausahaan yang berdasarkan religiusitas memiliki manfaat besar untuk pencapaian keuntungan perusahaan menghadapi peningkatan kompleksitas antara pelanggan dan para pemegang saham (Wilbard, 2009)

\section{Islam dan Kewirausahaan}

Untuk meraih kesejahteraan hidup di dunia dan akhirat, Islam tidak hanya mengajarkan kepada pemeluknya untuk beribadah mahdah, tapi juga sangat mendorong umatnya untuk bekerja keras, kendati demikian bukan berarti tanpa kendali. Antara iman dan amal harus ada interaksi. Artinya, betapapun keras nya usaha yang dilakukan, harus selalu dalam bingkai hukum Islam. Dan salah satu kerja keras yang didorong Islam adalah berwirausaha. Kata wirausaha dalam istilah asingnya dikenal sebagai enterpreneur. 
Kewirausahaan adalah semangat, sikap, perilaku dan kemampuan seseorang dalam menangani usaha dan kegiatan yang mengarah pada upaya mencari, menciptakan, menerapkan cara kerja, teknologi dan produk baru yang dilakukan berdasarkan Ridho-Nya, karena semuanya akan dikembalikan kepadaNya. Karena lahir-mati, takdir dan rezeki adalah merupakan kekuasaan absolut di luar instrumen rasionalitas manusia.

Semagat kewirausahaan dalam kalangan muslim juga terlihat dari pepatah bahasa Arab "Inna al-samaa la tumtiru dzahaban wa la fidhatan" di mana diartikan langit tidak menurunkan hujan emas dan perak, tetapi perlu dengan semangat kerja yang tidak mengenal lelah. Atau kata hikmah yang bisa diimplimentasikan ke kehidupan yang nyata "isy ka annaka ta'isyu abada" atau "I'mal lid dunyyaka kaannakata'isyu abada". Dimana terminologi "berkerjalah bagi duniamu seakan-akan kamu hidup abadi" yang menunjukkan kepada semua orang bahwa etos kerja orang muslim sangat bisa untuk diandalkan. Allah SWT berfirman dalam surat Al-Jumu'ah ayat 10 :

"Apabila telah ditunaikan shalat, maka bertebaranlah kamu di muka bumi; dan carilah karunia Allah dan ingatlah Allah banyak-banyak supaya kamu beruntung”.

Dari ayat tersebut di atas Alla memerintahkan kepada kita untuk menunaikan kewajiban kita kepada-Nya yang pada gilirannya nanti Allah pun akan memberikan hak hambanya yang senantiasa patuh dan taat kepada-Nya.

Kewirausahaan adalah bagian dari ekonomi Islam dan bisnis. Kewirausahaan adalah mengejar peluang luar sumber daya yang dikendalikan. Nabi Muhammad SAW dan para sahabatnya adalah contoh yang harus diteladani berkaitan dengan kewirausahaan. Islam bukanlah berlawanan dengan kewirausahaan. Islam mengajak semua Muslim untuk menjadi pengusaha dalam kehidupan mereka dengan diberikan aturan yang harus diikuti oleh semua Muslim yang berasal dari al-Quran dan al-Hadis (Faizal, Ridhwan, \& Kalsom, 2013). AlQur'an dan al-Hadis inilah yang menjadi sumber nilai, sikap, perilaku, dan etika seorang muslim dalam berwirausaha.

\section{METODE}

Studi ini akan menggunakan analisis isi sebagai sebuah pendekatan dalam analisis data. Analisis isi adalah metode untuk menganalisa dokumen untuk menggambarkan dan mengukur fenomena secara sistematis dan objektif (DowneWamboldt, 1992; Elo \& Kyngäs, 2008; Sandelowski, 1995). Hal ini telah memungkinkan peneliti meningkatkan pemahaman tentang data dengan menguji masalah teoritis. 


\section{PEMBAHASAN}

Studi ini ingin menjelaskan kewirausahaan dengan mengembangkan konsep kewirausahaan melalui perspektif religiusitas. Studi ini menawarkan alternatif perspektif bahwa religiusitas menjadi faktor-faktor yang dapat mempengaruhi kinerja. Dalam konteks kewirausahaan, agama akan mempengaruhi sikap dan perilaku wirausaha melalui penciptaan nilai, menjalankan kegiatan bisnis dengan lebih menekankan pada moral dan etika bisnis (Steinberg, 2010).

Agama pada dasarnya sebuah sistem kepercayaan. Sebagai sistem keyakinan yang berfungsi sebagai pedoman dalam melakukan hidup, agama dapat juga digunakan sebagai panduan dalam melakukan kegiatan bisnis. Meskipun demikian, masih sangat sedikit penelitian yang menggunakan pendekatan religiusitas dalam kaitannya dengan pencapaian kinerja perusahaan. Umumnya, beberapa peneliti mengembangkan konsep kewirausahaan dengan lebih menekankan pada kewirausahaan dalam sikap, perilaku dan proses. Di satu sisi, perspektif religiusitas ini juga mampu menggambarkan tiga perspektif pengembangan konsep kewirausahaan. Beberapa penelitian telah dilakukan untuk menjelaskan sistem kepercayaan mampu menggambarkan bagaimana sikap yang harus ditunjukkan oleh seorang wirausaha, perilaku dan proses. Sebagai contoh, sebuah studi yang dilakukan oleh Iannaccone (1998); Audretsch, et al. (2013), menunjukkan bahwa religiusitas akan mempengaruhi keputusan seseorang untuk menjadi kewirausahaan.

Untuk menjelaskan hubungan antara religiusitas dan sikap individu dan perilaku, kami menggunakan pendapat seperti yang diungkapkan oleh Dood (1998); Carswell dan Rolland (2007) bahwa religiusitas akan mempengaruhi sikap dan perilaku wirausaha. Sikap dan perilaku individu dapat dilihat dari bagaimana mereka menjalankan kegiatan bisnis. Selain itu, sikap dan perilaku yang ditunjukkan dapat digunakan untuk mengidentifikasi peluang dan mengembangkan bisnis. Dalam pandangan kami, sikap dan perilaku yang ditunjukkan oleh religiusitas individu cenderung untuk menjalankan kegiatan usaha dengan lebih menekankan pada etika dan moral. Etika dalam menjalankan bisnis dan moralitas yang pada akhirnya akan membentuk nilai-nilai kewirausahaan. Sementara beberapa peneliti menggunakan dimensi yang inovatif, proaktif dan berani mengambil risiko untuk mengukur pencapaian kinerja kewirausahaan, maka ia dapat dijelaskan dengan perspektif yang berbeda dalam konsep religiusitas (Covin \& Slevin, 1991; Zahra, 1993). Sebagai contoh, dimensi keberanian mengambil risiko dalam perspektif Islam. Orang yang religius mungkin tidak akan menggunakan dimensi ini dalam mengembangkan usaha karena dalam keyakinan disokong dilihat pada perilaku yang menghasilkan tidak pasti. Oleh karena itu, orang yang religius akan melakukan pengembangan bisnis dengan cara yang sesuai dengan aturan yang ada. Akibatnya, pengembangan usaha tidak dapat dilakukan dengan cepat, tetapi berkat Allah akan berfungsi sebagai landasan utama

Pada akhirnya, religiusitas akan mempengaruhi kinerja dan prestasi kewirausahaan. Beberapa studi sebelumnya menyatakan bahwa, ketika religiusitas individu mampu berperan sebagai faktor-faktor yang membedakan dengan individu yang lain, maka itu akan menimbulkan konsekuensi dari perbedaan dalam pencapaian kinerja. Sikap dan perilaku sebagai akibat dari religiusitas akan 
mendorong orang untuk bertindak dalam kinerja yang proaktif, inovatif dan unggul sehingga dapat dicapai (Botsaris \& Vamvaka, 2012; Zulkifli \& Rosli, 2013). Pencapaian kinerja yang unggul karena adanya nilai yang dimiliki oleh seorang individu dalam melaksanakan kegiatan usaha. Dalam konteks ini, kinerja dapat dilihat dari pencapaian tingkat keuntungan, pangsa pasar dan pertumbuhan atau non keuangan kinerja (Chandrakumara, De Zoysa, \& Manawaduge, 2011). Lebih luas lagi, pencapaian kinerja yang diterima wirausaha yang menerapkan prinsipprinsip religiusitas juga dapat dilihat dari peningkatan kinerja ekonomi ( Galbraith \& Galbraith, 2007; Dana, 2010; Fitzsimmons \& Douglas, 2005; Jong, 2008; McCleary \& Barro, 2006).

\section{KESIMPULAN}

Dalam konteks kewirausahaan, agama akan mempengaruhi sikap dan perilaku wirausaha melalui penciptaan nilai, menjalankan kegiatan bisnis dengan lebih menekankan pada moral dan etika bisnis

Beberapa studi sebelumnya menyatakan bahwa, ketika religiusitas individu mampu berperan sebagai faktor-faktor yang membedakan dengan individu yang lain, maka itu akan menimbulkan konsekuensi dari perbedaan dalam pencapaian kinerja.

\section{DAFTAR PUSTAKA}

Antoncic , B., \& Hisrich , Robert D. . (2003). Clarifying the intrapreneurship concept. Journal of Small Business and Enterprise Development, 10(1), 7-24. http://doi.org/10.1108/14626000310461187

Carswell, P., \& Rolland, Deborah. (2007). Religion and entrepreneurship in New Zealand. Journal of Enterprising Communities: People and Places in the Global Economy, 1(2), 162-174. http://doi.org/10.1108/17506200710752584

Galbraith, C. S., \& Galbraith, Devon M. (2007). An empirical note on entrepreneurial activity, intrinsic religiosity and economic growth. Journal of Enterprising Communities: People and Places in the Global Economy, 1(2), 188-201. http://doi.org/10.1108/17506200710752601

Noble, A. De, Galbraith, Craig S., Singh, Gangaram, \& Stiles, Curt H. (2007). Market justice, religious orientation, and entrepreneurial attitudes: An empirical study. Journal of Enterprising Communities: People and Places in the Global Economy,1(2),121-134. tp://doi.org/10.1108/17506200710752548 
Valliere, D. (2008). Exploring Buddhist influence on the entrepreneurial decision. International Journal of Entrepreneurial Behaviour \& Research, 14(3), 172191. http://doi.org/10.1108/13552550810874682

Adamu, I. M., Kedah, Z., \& Osman-gani, A. (2011). Entrepreneurial Motivation, Performance and Commitment to Social Responsibility: A Conceptual Analysis on the Influence of Islamic Religiosity. In 10th International Conference of the Academy of HRD (pp. 1-33).

Arief, M. (2013). A Theoretical Review of Entrepreneurship: The Effect of Religiosity to the Performance. International Conference on Entrepreneurship and Business Management (ICEBM 2013): Sanur, Bali November 21-22, 2013, (November), 337-345.

Audretsch, D., Boente, W., \& Tamvada, J. (2007). Religion and entrepreneurship. Retrieved from http://papers.ssrn.com/sol3/papers.cfm?abstract_id=1136703

Baharun, R., \& Kamarudin, S. (2001). the Effects of Entrepreneurs' Personal Religious Values and Business Performance in Information Technology Industry. Journal of Enterprising Culture, 9(4), 437-448. http://doi.org/10.1142/S0218495801000225

Balog, A. M., Baker, L. T., \& Walker, A. G. (2014). Religiosity and spirituality in entrepreneurship: a review and research agenda. Journal of Management, Spirituality \& Religion, 11(12), 159-186. http://doi.org/10.1080/14766086.2013.836127

Bergman, J. B., \& Brodd, H. M. (2014). How National Values Influence Entrepreneurial Behaviour. ECTS.

Botsaris, C. A., \& Vamvaka, V. (2012). Models of the determinants of entrepreneurial behaviour: A literature review. Regional Science Inquiry Journal, 4(3 SPEC. ISSUE), 155-172.

Busenitz, L. W., Gómez, C., \& Spencer, J. W. (2000). Country institutional profiles: Unlocking entrepreneurial phenomena. Academy of Management Journal, 43(5), 994-1003. http://doi.org/10.2307/1556423

Chandrakumara, A., De Zoysa, A., \& Manawaduge, A. (2011). Effects of the Entrepreneurial and Managerial Orientations of Owner-Managers on Company Performance: An Empirical Test in Sri Lanka. International Journal of Management, 28(1), 139-158. Retrieved from Covin, J. G., \& Slevin, D. P. (1991). A Conceptual Model of Entrepreneurship as Firm Behavior. Entrepreneurship: Theory \& Practice, 16(1), 7-25. http://doi.org/1042-2587-91-161 
Dana, L.-P. (2010). Entrepreneurship and Religion.

Dilmaghani, M. (2011). Religiosity, human capital return and earnings in Canada. International Journal of Social Economics, 39(1/2), 55-80. http://doi.org/10.1108/03068291211188875

Dodd, S. D., \& Gotsis, G. (2007). An Examination of The interrelationships between entrepreneurship and religion. The International Journal of Entrepreneurship and Innovation, 8(2), 93-104. http://doi.org/10.5367/000000007780808066

Dodd, S. D., \& Seaman, P. T. (1998). Religion and Enterprise: An Introductory Exploration. Entrepreneurship Theory and Practice, 71-87.

Downe-Wamboldt, B. (1992). Content analysis : Method, applications, and issues. Health Care for Women International, 13(3), 313-321.

Duygulu, E., \& Kurgun, O. A. (2009). The effect of managerial entrepreneurship behavior on employee satisfaction: Hospitality managers' dilemma. African Journal of Business Management, 3(11), 715-726. http://doi.org/10.5897/AJBM09.235

Elo, S., \& Kyngäs, H. (2008). The qualitative content analysis process. Journal of Advanced Nursing, 62(1), 107-115. http://doi.org/10.1111/j.13652648.2007.04569.x

Emami, M., \& Nazari, K. (2012). Entrepreneurship, Religion, and Business Ethics. Australian Journal of Business and Management Research, 1(11), 59-69.

Faizal, P. R. M., Ridhwan, A. A. M., \& Kalsom, A. W. (2013). The Entrepreneurs Characteristic from al-Quran and al-Hadis. International Journal of Trade, Economics and Finance, 4(4), 191-196. http://doi.org/10.7763/IJTEF.2013.V4.284

Fitzsimmons, J., \& Douglas, E. J. (2005). Entrepreneurial Attitudes and Entrepreneurial Intentions : a Cross-Cultural Study of Potential Entrepreneurs in India , China, Thailand and Australia . Applied Optics, 47(June), 1-20. Retrieved from http://www.ncbi.nlm.nih.gov/pubmed/21198165

Halis, M., Ozsabuncuoglu, I. H., \& Ozsagir, a. (2007). the Values of Entrepreneurship and Factors That Effect Entrepreneurship : Findings From Anatolia. Serbian Journal of Management, 2(1), 21-34.

Hill, J., \& Wright, L. T. (2000). Defining the Scope of Entrepreneurial Marketing: A Qualitative Approach. Journal of Enterprising Culture, 8(1), 23-46. 
Iannaccone, L. R. (1998). Introduction to the Economics of Religion. Journal of Economic Literature, 36(3), 1465-1495. http://doi.org/10.1016/j.religion.2008.01.006

Jong, E. De. (2008). Religious Values and Economic Growth: A review and assessment of recent studies. NiCE Working Paper 08-111, (November), 134.

Kohl, J. P. (1984). Strategies for growth: Intervention in a church. Long Range Planning, 17(6), 76-81. http://doi.org/10.1016/0024-6301(84)90220-6

Lumpkin, G. T., \& Dess, G. G. (1996). Clarifying the entrepreneurial orientationconstruct and linking it to performance. Academy of Management Review, 21(1), 135-172.

Makhbul, Z. M., \& Hasun, F. M. (2011). Entrepreneurial Success : An Exploratory Study among Entrepreneurs. International Business and Management, 6(1), $116-125$.

McCleary, R. M., \& Barro, R. J. (2006). Religion and Economy. Journal of Economic Perspectives, 20(2), 49-72. http://doi.org/10.1257/jep.20.2.49

McDaniel, S. W., \& Burnett, J. J. (1990). Consumer religiosity and retail store evaluative criteria. Journal of the Academy of Marketing Science, 18(2), 101112. http://doi.org/10.1007/BF02726426

Morris, M. H., Lewis, P. S., \& Sexton, D. L. (1994). Reconceptualizing entrepreneurship: An Input-Output Perspective. SAM Advanced Management Journal, 59(1), 21-31.

Morrison, A. (2000). Entrepreneurship: what triggers it? International Journal of Entrepreneurial Behavior \& Research, 6(2), 59-71. $\mathrm{http} / / /$ doi.org/10.1108/13552550010335976

Muhamad, N., \& Mizerski, D. (2010). The constructs mediating religions' influence on buyers and consumers. Journal of Islamic Marketing, 1(2), 124135. http://doi.org/10.1108/17590831011055860

Naughton, M., \& Cornwall, J. R. (2009). Culture as the Basis of The Good Entrepreneur. Journal of Religion \& Business Ethics, 1(1), 1-13.

Patel, M. (2003). Influence of Religion on Shopping Behaviour of Consumers-an Exploratory Study. Journal of Research in Commerce \& Management, 1(5), $68-78$. 
Robinson, P. B., Stimpson, D. V., Huefner, J. C., \& Hunt, H. K. (1991). An Attitude Approach to the Prediction of Entrepreneurship. Entrepreneurship Theory and Practice, 15(4), 13-31.

Sandelowski, M. (1995). Qualitative analysis: what it is and how to begin. Research in Nursing \& Health, 18(4), 371-375. http://doi.org/10.1002/nur.4770180411

Shane, S., \& Venkataraman, S. (2000). The Promise Of Entrepreneurship as a Filed of Research. The Academy of Management Review, 25(1), 217-226.

Shariff, M. N. M., \& Saud, M. B. (2009). An Attitude Approach to the Prediction of Entrepreneurship on Students at Institution of Higher Learning in Malaysia. International Journal of Business and Management, 4(4), 129-135.

Sood, J., \& Nasu, Y. (1995). Religiosity and Nationality An Exploratory Study of Their Effect on Consumer Behavior in Japan and the United States. Journal of Business Research, 34(94), 1-9. http://doi.org/ISSN 0148-2963/95/\$9.50

Steinberg, A. (2010). Is Moral Entrepreneurship Tied to Religiosity?

Stevenson, H. H., \& Jarillo, J. C. (1990). A Paradigm of Entrepenreurship: Entrepreneurial Management. Strategic Management Journal, 11, 17-27. Retrieved from papers2://publication/uuid/3D4B55C7-CB0B-4C94-945BD2D5FCD6FF70

Wilbard, F. (2009). Entrepreneurship Proclivity: An exploratory study on Students 'entrepreneurship intention. University of Agder.

Worthington, Everett L., J., Wade, N. G., Hight, T. L., Ripley, J. S., McCullough, M. E., Berry, J. W., ... O'Connor, L. (2003). The Religious Commitment Inventory: Development, refinement, and validation of a brief scale for research and counseling. Journal of Counseling Psychology, 50(1), 84-96. http://doi.org/10.1037/0022-0167.50.1.84

Zahra, S. A. (1993). A Conceptual Model of Entrepreneurship as Firm Behavior: A Critique and Extension. Entrepreneurship: Theory \& Practice, 5-21. http://doi.org/1042-2587-91-161

Zulkifli, R. M., \& Rosli, M. M. (2013). Entrepreneurial Orientation and Business Success of Malay Entrepreneurs: Religiosity as Moderator. International Journal of Humanities and Social Science, 3(10), 264-275. 